\title{
Compliance to Dietary Counselling in Controlling Blood Lipid and its Barriers among Dyslipidemic Individuals
}

\author{
Suhaina Sulaiman ${ }^{\#}$, Zahara Abdul Manaf \# , Mohd Razif Shahril*,€ \\ \# Dietetics Programme, School of Healthcare Sciences, Faculty of Health Sciences, Universiti Kebangsaan Malaysia, \\ 50300 Kuala Lumpur, Malaysia \\ E-mail: suhaina.hjsulaiman@ukm.edu.my; zaharamanaf@ukm.edu.my
}

* Institute for Community (Health) Development, Universiti Sultan Zainal Abidin, Gong Badak Campus, Kuala Nerus, 21300 Terengganu, Malaysia

\author{
${ }^{\epsilon}$ School of Nutrition and Dietetics, Faculty of Health Sciences, Universiti Sultan Zainal Abidin, Gong Badak Campus, Kuala Nerus, \\ 21300 Terengganu, Malaysia \\ E-mail: razifshahril@unisza.edu.my
}

\begin{abstract}
Dyslipidemia is a risk factor causing cardiovascular disease and compliance to dietary counselling results in an improved lipid profile. The present study aimed to assess the compliance to dietary counselling and its barriers among dyslipidemic individuals attending dietary follow-ups counselling in Diet Clinic of Universiti Kebangsaan Malaysia Medical Centre (UKMMC). A cross sectional study using the convenience sampling technique was conducted from May to June 2012. Data on food intake, lifestyle habits, physical activity level and barriers in adhering to dietary counselling were collected using interview-based questionnaires. Anthropometric measurements were conducted, while blood lipid profile and medical information were obtained from medical records. The results showed that non-compliance is prevalent among dyslipidemic patients who received dietary counselling. Most subjects $(81 \%)$ were unable to achieve at least four of the therapeutic lifestyle change dietary recommendations as outlined by National Cholesterol Education Program Adult Treatment Panel III. Factors such as time, food taste and price have been reported as the main barriers to comply towards dietary counselling. A significantly higher proportion of those in non-compliance group did not meet total fat $(p<0.001)$ and saturated fat $(p<0.001)$ recommendations as compared to the compliance group. In conclusion, acknowledgements of barriers while providing dietary education are necessary to improve dyslipidemic patients' compliance with controlling blood lipid.
\end{abstract}

Keywords - compliance; barriers; dietary counselling; dyslipidemia; blood lipid

\section{INTRODUCTION}

Dyslipidemia is widely known as main risk factors for cardiovascular disease (CVD) and coronary heart disease (CHD) [1], [2]. Prominent relationship is found between lowering of blood cholesterol level and incidence of cardiovascular disease, in which $1 \%$ drop in cholesterol levels reduces cardiovascular disease incidence by $1 \%$ [3]. In 2009, cardiovascular disease is the leading cause of death in both men and women in Malaysia [4]. Malaysian NCVDACS Registry 2010-2012 demonstrated that dyslipidemia was present in $70.8 \%$ of the patients [5].

National Cholesterol Education Program (NCEP) established Therapeutic Lifestyle Changes (TLC) diet, a cholesterol lowering diet aimed to reduce patients' risk of heart disease [6]. Two critical components emphasized by
American Heart Association in reducing cardiovascular disease risk in the general population are through improving diet and lifestyle. Lifestyle interventions by reducing total calories, saturated and trans-fat intake together with an increase in physical activity with associated weight loss plays significant role in controlling mixed dyslipidemia [7].

Despite all efforts paid by healthcare professionals, intended outcomes might not be achievable if the patient is non-compliant and results in poor disease management [8]. Several barriers to healthy eating includes cost, lack of time, self-control, selection influences, lack of knowledge, unpleasant foods and resistance to change [9].

Therefore, this study was conducted to assess the compliance towards dietary counselling in controlling blood lipid among dyslipidemic individuals. The study also 
explored the major perceived barriers affecting patients' compliance in order to enhance dietary compliance.

\section{MATERIAL AND METHOD}

\section{A. Study Design}

A cross-sectional study recruited 43 dyslipidemic patients in Diet Clinic of Faculty of Health Sciences, Universiti Kebangsaan Malaysia Medical Centre (UKMMC). Ethical approval of this study was obtained from the Medical Research Ethics Committee of Universiti Kebangsaan Malaysia Medical Centre (UKMMC) (UKM 1.5.3.5/138/NN-045-2012).

\section{B. Subjects}

Subjects were selected using convenience sampling. Verbal and written consent were obtained from patients prior to the study. Eligible patients included those aged 18 years old and above, citizens of Malaysia, able to understand, read, write and communicate in Malay or English were diagnosed with dyslipidemia or dyslipidemia with another disease such as type II diabetes mellitus, hypertension or obesity on at least first dietary follow-up counselling session with a dietitian in Diet Clinic, Faculty of Health Sciences, UKMMC. The exclusion criteria for this study were patients with dyslipidemia and renal failure, hepatic or cancer, had mental health problems, were deaf or mute, had problems in doing physical activity such as nerve problem and locomotion like paralyze and patient who failed to attend dietary follow-up counselling with a dietitian.

\section{Data Collection}

Socio-demographic, food intake, lifestyle habits, physical activity level and barriers in compliance to dietary counselling were obtained using interview-based questionnaires. Serum lipid profile such as total cholesterol, LDL cholesterol, HDL cholesterol, triglycerides and clinical profile including hypolipidemic medication prescription were obtained from the patients' medical records. Anthropometric data were obtained by conducting anthropometric measurements including weight, height, waist circumference and body fat percentage using the standard technique. Weight and height were measured using SECA 703 High Capacity Digital Medical Scale (Model 703, SECA, Germany) with sensitivity of $\pm 0.1 \mathrm{~kg}$ and SECA body meter 220 (Model 220, SECA, Germany) to the nearest $0.1 \mathrm{~cm}$, respectively. Waist circumference was measured using a non-elastic measuring tape and was recorded to sensitivity $\pm 0.1 \mathrm{~cm}$ while body fat percent was measured using the Omron body fat monitor (Model HBF 306, Omron, Germany) with sensitivity of $\pm 0.1 \%$. Body mass index (BMI) of each subject was calculated by using the formula: Weight $(\mathrm{kg}) /$ Height $\left(\mathrm{m}^{2}\right)$ and being classified based on WHO [10]. The cutoff point of waist circumference was compared to the recommendation from WHO/IASO/IOTF [11], while body fat percent based on normal range used in the Department of Diagnostic Laboratory Services UKMMC which are 10-20\% for male and $20-30 \%$ for female. Food intake was collected using 24 Hours Interactive Diet Recall and Food Intake Pattern Questionnaire adapted from [12]. Physical activity data were obtained by using the short form of the
International Physical Activity Questionnaire (IPAQ) which has been validated [13]. Barriers in compliance towards dietary counselling were obtained by using questionnaires adapted from [14].

Nutritionist Pro version 3.1.0 was used to estimate the energy and nutrient from diet recall and compared to the therapeutic lifestyle changes diet guidelines established by NCEP ATP III [6]. Subjects were classified into two groups, those who were able to achieve at least four recommendations (namely total energy, total fat, saturated fat and polyunsaturated fat) were considered 'compliance', this did not were in the 'non-compliance' group. The total cholesterol level was used to determine dyslipidemic control where subjects with less than $5.7 \mathrm{mmol} / \mathrm{L}$ were classified as good dyslipidemic control, while those exceeded this value were having poor dyslipidemic control.

\section{Statistical Analysis}

The Statistical Package for Social Sciences (SPSS) version 20.0 (SPSS Inc., Chicago, IL, USA) was used to analyze all the data. Descriptive statistics including mean, range and standard deviation were reported for baseline subject characteristics, barriers in compliance towards dietary counselling. Chi Square test and Fisher's Exact tests were used to compare compliance towards dietary counselling and subject characteristics as well as nutrient intake.

\section{RESULTS AND DISCUSSION}

A total of 43 patients participated in the study (14 males) with an age range of 28 to 73 years and a mean age of 52.6 years. The breakdown by race showed that Malay constituted the highest ethnic which are $67.4 \%$, followed by Chinese (25.6\%), Indian (4.7\%) and Sarawak Natives (2.3\%). Majority of the subjects were married (88.4\%), had completed secondary school education (58.1\%) with a household income of around RM1500-RM3000 (44.2\%).

Table I illustrates the characteristics of subjects in association to compliance to dietary counselling. A vast majority of subjects did not comply towards dietary counselling (81\%), in terms of comparison of nutrient intake with guidelines from NCEP ATP III [18]. Women made up a higher percentage of those who comply $(87.5 \%)$ and do not comply $(62.9 \%)$. No significant difference $(\mathrm{p}>0.05)$ was found where age, gender, anthropometric measurements, fasting serum lipids, hypolipidemic medication prescription and compliance, types of therapy, dyslipidemic control, frequency of dietary follow-up counselling, lifestyles including alcoholic intake, smoking habits and physical activity level do not determine individual's compliance. Higher proportion of subjects who complied to dietary counselling showed characteristics like being prescribed $(62.5 \%)$ and complied $(60 \%)$ to hypolipidemic medications and also a good control of dyslipidemia $(62.5 \%)$, but were engaged in a low physical activity level (75.0\%). Meanwhile, in the non-compliance group, higher percentage were those not prescribed with any hypolipidemic medication (54.3\%) or did not comply with prescribed hypolipidemic medication $(68.8 \%)$ have moderate and high levels of physical activity $(51.4 \%)$ with poor dyslipidemic control (54.3\%). Subjects in both groups were mostly receiving diet therapy only, have 
attended more than one follow-up of dietary counselling, non-smoker and non-alcoholic drinker.

Table II demonstrates the energy and nutrient intakes in relation to compliance to dietary counselling. Most subjects who complied to dietary counselling showed appropriate consumption of energy, carbohydrate, total fat, saturated fat, polyunsaturated fatty acids (PUFA) and dietary cholesterol as meeting the recommendations of NCEP ATP III [18], but not monounsaturated fatty acids (MUFA) and protein. A significantly higher proportion of those in non-compliance group did not meet total fat $(\mathrm{p}<0.001)$ and saturated fat $(\mathrm{p}<$ 0.001) intake recommendations of NCEP ATP III as compared to the compliance group. Most of those in noncompliance group also did not meet energy and carbohydrate intake recommendations. However, they had met PUFA and dietary cholesterol recommendations. Fiber intake of less than $20 \mathrm{~g}$ per day, is low for both groups of subjects.

TABLE I

CHARACTERISTICS OF SUBJECTS IN ASSOCIATION TO COMPLIANCE TO DIETARY COUNSELLING

\begin{tabular}{|c|c|c|c|}
\hline \multirow[t]{2}{*}{ Characteristics $^{\text {a }}$} & \multicolumn{2}{|c|}{ Compliance to Dietary Counselling } & \multirow[t]{2}{*}{ P-Value } \\
\hline & Yes $(\mathbf{n}=8)$ & No $(n=35)$ & \\
\hline Age, years & $51.7 \pm 15.6$ & $52.8 \pm 9.4$ & $0.650^{\mathrm{b}}$ \\
\hline $\begin{array}{l}\text { Gender, n (\%) } \\
\text { Men } \\
\text { Women }\end{array}$ & $\begin{array}{l}1(12.5) \\
7(87.5)\end{array}$ & $\begin{array}{l}13(37.1) \\
22(62.9)\end{array}$ & $0.240^{\mathrm{c}}$ \\
\hline $\begin{array}{l}\text { Body weight, kg } \\
\text { Men } \\
\text { Women }\end{array}$ & $\begin{array}{c}66.9 \\
63.5 \pm 10.1\end{array}$ & $\begin{array}{l}84.5 \pm 22.3 \\
72.4 \pm 14.3\end{array}$ & $\begin{array}{l}0.264^{b} \\
0.108^{b}\end{array}$ \\
\hline $\begin{array}{l}\text { Body height, } \mathrm{cm} \\
\text { Men } \\
\text { Women }\end{array}$ & $\begin{array}{c}164.0 \\
150.3 \pm 5.3 \\
\end{array}$ & $\begin{array}{l}165.4 \pm 7.2 \\
152.9 \pm 4.5 \\
\end{array}$ & $\begin{array}{l}0.901^{\mathrm{b}} \\
0.176^{\mathrm{b}}\end{array}$ \\
\hline $\begin{array}{l}\text { Body mass index, } \mathrm{kg} / \mathrm{m}^{2} \\
\text { Men } \\
\text { Women }\end{array}$ & $\begin{array}{c}24.9 \\
28.0 \pm 3.6\end{array}$ & $\begin{array}{l}30.6 \pm 6.0 \\
31.1 \pm 6.4\end{array}$ & $\begin{array}{l}0.172^{b} \\
0.273^{b}\end{array}$ \\
\hline $\begin{array}{l}\text { Waist circumference, } \mathrm{cm} \\
\text { Men } \\
\text { Women }\end{array}$ & $\begin{array}{c}107.0 \\
88.0 \pm 8.7\end{array}$ & $\begin{array}{l}94.8 \pm 6.5 \\
87.2 \pm 6.0\end{array}$ & $\begin{array}{l}0.127^{b} \\
0.777^{b}\end{array}$ \\
\hline $\begin{array}{l}\text { Body fat percent, } \mathrm{n}(\%) \\
\text { Men } \\
\text { Women }\end{array}$ & $\begin{array}{c}32.7 \\
39.5 \pm 2.3\end{array}$ & $\begin{array}{l}33.2 \pm 4.7 \\
40.2 \pm 3.7\end{array}$ & $\begin{array}{l}0.901^{b} \\
0.614^{b}\end{array}$ \\
\hline Total cholesterol, $\mathrm{mmol} / \mathrm{L}$ & $5.21 \pm 1.09$ & $5.58 \pm 1.11$ & $0.333^{b}$ \\
\hline Triglycerides, $\mathrm{mmol} / \mathrm{L}$ & $1.47 \pm 0.64$ & $1.77 \pm .72$ & $0.296^{\mathrm{b}}$ \\
\hline HDL cholesterol, $\mathrm{mmol} / \mathrm{L}$ & $1.43 \pm 0.44$ & $1.33 \pm .43$ & $0.522^{b}$ \\
\hline LDL cholesterol' $\mathrm{mmol} / \mathrm{L}$ & $2.98 \pm 0.98$ & $3.44 \pm 1.01$ & $0.281^{\mathrm{b}}$ \\
\hline $\begin{array}{l}\text { Prescribed with hypolipidemic medication, n (\%) } \\
\text { Yes } \\
\text { No }\end{array}$ & $\begin{array}{l}5(62.5) \\
3(37.5)\end{array}$ & $\begin{array}{l}16(45.7) \\
19(54.3)\end{array}$ & $0.457^{\mathrm{c}}$ \\
\hline $\begin{array}{l}\text { Compliance to hypolipidemic medication, n (\%) } \\
\text { Yes } \\
\text { No }\end{array}$ & $\begin{array}{l}3(60.0) \\
2(40.0) \\
\end{array}$ & $\begin{array}{c}5(31.2) \\
11(68.8) \\
\end{array}$ & $0.325^{\mathrm{c}}$ \\
\hline $\begin{array}{l}\text { Types of therapy, } \mathrm{n}(\%) \\
\text { Diet therapy } \\
\text { Diet }+ \text { hypolipidemic medication }\end{array}$ & $\begin{array}{l}5(62.5) \\
3(37.5)\end{array}$ & $\begin{array}{c}30(87.5) \\
5(14.3)\end{array}$ & $0.153^{\mathrm{c}}$ \\
\hline $\begin{array}{l}\text { Dyslipidemic control, } \mathrm{n}(\%) \\
\text { Good control } \\
\text { Poor control }\end{array}$ & $\begin{array}{l}5(62.5) \\
3(37.5)\end{array}$ & $\begin{array}{l}16(45.7) \\
19(54.3)\end{array}$ & $0.457^{\mathrm{c}}$ \\
\hline $\begin{array}{l}\text { Frequency of dietary follow-up counselling, n (\%) } \\
\text { Once } \\
\text { More than once }\end{array}$ & $\begin{array}{l}3(37.5) \\
5(62.5) \\
\end{array}$ & $\begin{array}{l}13(37.1) \\
22(62.9) \\
\end{array}$ & 1.000 \\
\hline $\begin{array}{l}\text { Alcohol intake, n (\%) } \\
\text { Drinker } \\
\text { Non-drinker }\end{array}$ & $\begin{array}{c}0(0.0) \\
8(100.0)\end{array}$ & $\begin{array}{c}3(8.6) \\
32(91.4) \\
\end{array}$ & 1.000 \\
\hline $\begin{array}{l}\text { Smoking habit, n (\%) } \\
\text { Smoker } \\
\text { Non-smoker }\end{array}$ & $\begin{array}{c}0(0.0) \\
8(100.0)\end{array}$ & $\begin{array}{c}4(11.4) \\
31(88.6)\end{array}$ & 1.000 \\
\hline $\begin{array}{l}\text { Physical activity level, n (\%) } \\
\text { Low } \\
\text { Moderate or high }\end{array}$ & $\begin{array}{l}6(75.0) \\
2(25.0)\end{array}$ & $\begin{array}{l}17(48.6) \\
18(51.4)\end{array}$ & $0.250^{\mathrm{c}}$ \\
\hline
\end{tabular}

a Data were presented as mean \pm standard deviation otherwise stated.

${ }^{b}$ No significant difference based on Mann-Whitney test $(\mathrm{p}>0.05)$

${ }^{c}$ No significance based on Fisher's Exact test ( $\left.p>0.05\right)$ 
Barriers influencing compliance to dietary counselling among subjects were outlined in Fig. 1. Results showed that time, food taste and price were three most common barriers faced by subjects. These were followed by self-control, social and knowledge as reported barriers. Positive effect, disbelief and disinterest were less commonly reported as barriers while self-image was the least reported barrier.

A high proportion of subjects $(81 \%)$ did not comply towards dietary counselling, as the findings show they did not meet at least four dietary recommendations established by NCEP ATP III (2002) [6], namely total energy, total fat, saturated fatty acids (SFA) and polyunsaturated fatty acids (PUFA) intake. Women were mostly those complied (88\%) and did not comply $(63 \%)$. This may be explained by the higher number of women subjects $(67 \%)$ in this study. However, a study found that adherence to NCEP lifestyle recommendations was lower among women who were not receiving nutritional advice [15].

The present study found that subjects who complied with dietary counselling also have good dyslipidemic control, with $62.5 \%$ of them currently only depending on diet as therapy. The other $37.5 \%$ were depending on both diet and hypolipidemic medications. In the non-compliance group, $87.5 \%$ of them currently depending on diet as therapy, $68.8 \%$ of them were also not taking hypolipidemic medications. However, not much difference (8.6\%) was found in the percentage of non-compliance subjects showing good or poor dyslipidemic control. A study reported that adherence to medication is still poor among patients who received lipid-lowering therapy, which explained subjects' non-compliance to hypolipidemic medications in the present study [16]. A Korean study revealed that being a current smoker, new user, no concurrent medication and presence of adverse reactions were patient-related factors for noncompliance with prescribed medications [17]. It is well recognized that dyslipidemia is one of the main risk factors for developing cardiovascular disease [1]. Therefore, subjects those did not manage a diet, did not comply with hypolipidemic medications and with poor dyslipidemic control might be at higher risk of cardiovascular disease.

According to a fasting lipid serum profile, noncompliance group also showed higher levels of total cholesterol, LDL cholesterol and triglycerides than the compliance group. Earlier research found that subjects who received and complied towards dietary counselling by taking food recognized to be cholesterol-lowering is very effective in lowering LDL cholesterol levels [18]. The present study also identified that number of dietary counselling does not predict nor influence patients' compliance rate. Nevertheless, previous studies showed factors those have some positive effects on compliance to dietary advice including advice given by a dietitian and paying more frequent visits to dietitian [19].

TABLE II

COMPARISON OF ENERGY AND NUTRIENT INTAKE BETWEEN COMPLIANCE AND NON-COMPLIANCE GROUPS

\begin{tabular}{|l|c|c|c|}
\hline \multicolumn{1}{|c|}{ Characteristics $^{\text {a }}$} & \multicolumn{2}{|c|}{ Compliance to Dietary Counselling } & \multirow{2}{*}{ P-Value } \\
\cline { 2 - 3 } & Yes (n=8) & No (n =35) & 0.230 \\
\hline Met energy requirement & $5(62.5)$ & $12(34.3)$ & 0.119 \\
\hline $\begin{array}{l}\text { Carbohydrate (\% of energy) } \\
\text { Met recommendation (50-60\%) }\end{array}$ & $7(87.5)$ & $19(54.3)$ & 1.000 \\
\hline $\begin{array}{l}\text { Protein (\% of energy) } \\
\text { Met recommendation ( 15\%) }\end{array}$ & $3(37.5)$ & $14(40.0)$ & $0.001^{*}$ \\
\hline $\begin{array}{l}\text { Total fat (\% of energy) } \\
\text { Met recommendation }(25-30 \%)\end{array}$ & $8(100.0)$ & $5(14.3)$ & $0.001^{*}$ \\
\hline $\begin{array}{l}\text { Saturated fat }(\% \text { of energy) } \\
\text { Met recommendation }(<7 \%)\end{array}$ & $8(100.0)$ & $4(11.4)$ & 0.656 \\
\hline $\begin{array}{l}\text { Polyunsaturated fat }(\% \text { of energy) } \\
\text { Met recommendation }(\sim 10 \%)\end{array}$ & $7(87.5)$ & $25(71.4)$ & 0.240 \\
\hline $\begin{array}{l}\text { Monounsaturated fat }(\% \text { of energy) } \\
\text { Met recommendation }(\sim 20 \%)\end{array}$ & $2(25.0)$ & $19(54.3)$ & 1.000 \\
\hline $\begin{array}{l}\text { Dietary cholesterol }(\mathrm{mg} / \mathrm{d}) \\
\text { Met recommendation }(<200 \mathrm{mg})\end{array}$ & $6(75.0)$ & $24(68.5)$ & 0.230 \\
\hline $\begin{array}{l}\text { Dietary fiber (g/d) } \\
\text { Met recommendation }(20-30 \mathrm{~g})\end{array}$ & $5(62.5)$ & $12(34.3)$ & \\
\hline
\end{tabular}

${ }^{a}$ Data were presented as n (\%).

*significant differences $(\mathrm{p}<0.01)$ based on the Pearson Chi square test.

A significantly higher percentage of those in the noncompliance group did not meet total fat and saturated fat (SFA) recommendations as compared to the compliance group. This may be due to two main sources of SFA in Malaysian diet namely palm olein oil and coconut milk were highly consumed by subjects. Palm olein oil contains about the same amount of SFA and monounsaturated fatty acids (MUFA). The earlier Malaysian study reported that cooking oil was found to be the main source of fat intake among
Malaysians, with palm olein oil contributes greater than half of total fat intake [20]. Besides, this result also implies that the compliance group was more aware and cautious in fat and SFA intake to control their blood lipid levels. Nevertheless, it is necessary to reduce SFA intake as the World Health Organization and American Dietetic Association have advised that SFA is a risk factor for cardiovascular disease [21], [22]. 
In general, majority of subjects were able to meet PUFA and dietary cholesterol intake recommendations. Various studies proved that PUFA showed improvement effect on serum lipid profile. There is a decrease in LDL cholesterol level by $1 \mathrm{mmol} / \mathrm{L}$ when PUFA is used to replace SFA in diet (10\% of calories) and thereby reduces the risk for coronary heart disease [23]-[25]. Fiber intake is especially important in managing blood lipid levels, where its intake should achieve 20 to $30 \mathrm{~g}$ per day [6]. Dietary fiber provides beneficial physiological effects including laxation, blood cholesterol and blood glucose attenuation. However, all subjects in this study consumed low amount of dietary fiber. Dyslipidemic patients should increase their fiber intake as study showed that low fiber intake is associated with higher blood cholesterol level [26]. More specifically, about 2 to 10 $\mathrm{g}$ intake of soluble fiber per day helps in lowering total and LDL cholesterol levels [27], [28].

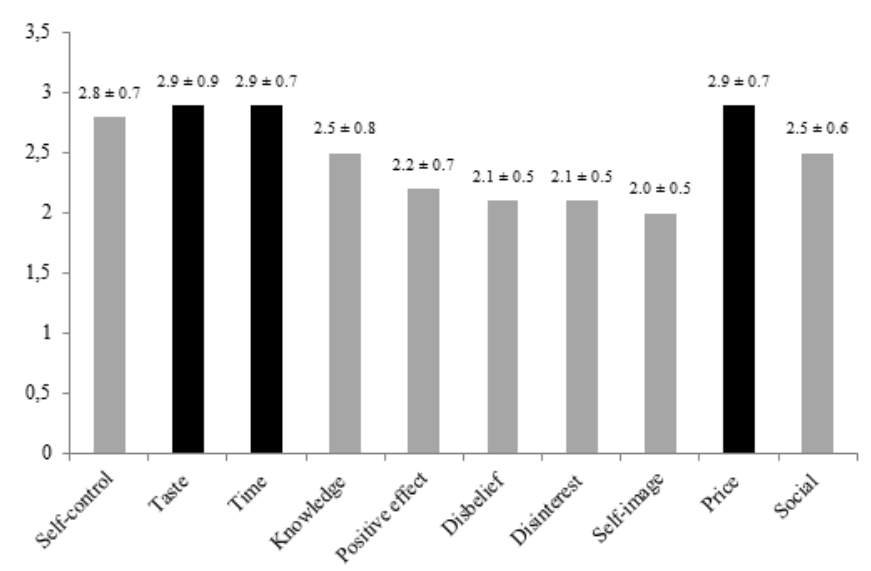

Fig. 1 Barriers reported by dyslipidemic subjects who had received dietary counselling (The values shown are mean and standard deviation for 5-point-

Likert scale. Response scale: $1=$ strongly disagree to $5=$ strongly agree)

Making dietary change is challenging. Time, food taste and price were reported as the main barriers (Fig. 1). This result was consistent with other studies. For instance, a study revealed that barriers to healthy eating include cost, lack of time and unpleasant food [9]. Time appears to be a barrier due to majority of subjects who were working and leading a busier life, where most meals, especially lunch were eaten outside. Eating outside has become more common dietary patterns since 20 years ago [29]. Previous study explained that women will cook meals at home if they have the cooking skills and confidence in cooking, have flexible work schedules or time [30]. A survey showed most of their participants agree that their life is so hectic they find it hard to include healthier food options on a daily basis [31].

As fat imparts taste and enhance palatability of food, lipid-lowering diet may not be satisfying the taste buds of subjects, making it a barrier to adapt to it. A study explained that human are more favorable towards the food they rate as tasty [32]. As for price factor, most subjects agreed that healthy foods are more expensive. The study showed that less healthy food, particularly those high in saturated fat and added sugar, tend to be high in calories with a low price per calorie. However, low calorie food, such as fruits and vegetables, appears to have higher price when the price was measured per calorie [33].

\section{CONCLUSIONS}

In conclusion, non-compliance is prevalent among dyslipidemic patients who received dietary counselling in Diet Clinic, Faculty of Health Sciences, UKMMC. Common reported barriers such as time, food taste and price are important implications for developing effective strategies to improve patients' compliance.

\section{ACKNOWLEDGMENT}

We would like to thank final year dietetic students, dieticians, staff and subjects in the Diet Clinic, Universiti Kebangsaan Malaysia Medical Centre for their assistance in data collection.

\section{REFERENCES}

[1] N. Wong, Y. Zhao, R. Patel, C. Patao, S. Malik, A. Bertonu, A. Correa, A. Folsom, S. Kachroo, J. Mukherjee, H. Taylor and E. Selvin, "Cardiovascular risk factor targets and cardiovascular disease event risk in diabetes: a pooling project of the atherosclerosis risk in communities study, multi-ethnic study of Atherosclerosis, and Jackson heart study," Diabetes Care, vol. 39, pp. 668-676, May 2016.

[2] R. L. McClelland, N. W. Jorgensen, M. Budoff, M. J. Blaha, W. S Post, R. A. Kronmal, D. E. Bild, S. Shea, K. Liu, K. E. Watson and A. R. Folsom, "10-year coronary heart disease risk prediction using coronary artery calcium and traditional risk factors: Derivation in the MESA (multi-ethnic study of Atherosclerosis) with validation in the HNR (Heinz Nixdorf Recall) study and the DHS (Dallas heart study)," Journal of the American College of Cardiology, vol. 66, pp. 1643-1653, Oct. 2015.

[3] S. M. Grundy, J. I. Cleeman, C. N. B. Merz, H. B. Brewer, L. T. Clark, D. B. Hunninghake, R. C. Pasternak, S. C. Smith and N. J. Stone. "Implications of recent clinical trials for the national cholesterol education program adult treatment panel III guidelines," Journal of the American College of Cardiology, vol. 44, pp. 720-732, Aug. 2004.

[4] Ministry of Health Malaysia, Number of Discharges and Deaths in Government Hospitals, Malaysia: Ministry of Health, 2010.

[5] W. A. Wan Ahmad and K. H Sim, Annual Report of the NCVD-PCI Registry, Year 2010-2012, Kuala Lumpur, Malaysia: National Cardiovascular Disease Database, 2014.

[6] National Cholesterol Education Program, National Heart, Lung and Blood Institute, National Institute of Health, Detection, Evaluation, and Treatment of High Blood Cholesterol in Adults (Adult Treatment Panel III), NIH Publication no. 02-5215, 2002.

[7] T. A. Pearson, L. P. Palaniappan, N. T. Artinian, M. R. Carnethon, M. H. Criqui, S. R. Daniels, G. C. Fonarow, S. P. Fortmann, B. A. Franklin, J. M. Galloway and D. C. Goff, "American Heart Association guide for improving cardiovascular health at the community level, 2013 update a scientific statement for public health practitioners, healthcare providers, and health policy makers," Circulation, vol. 127, pp. 1730-1753, Mar. 2013.

[8] J. Wu, S. Zhu, G. L. Yao, M. A. Mohammed and T. Marshall, "Patient factors influencing the prescribing of lipid lowering drugs for primary prevention of cardiovascular disease in UK general practice: A national retrospective cohort study," PLoS One, vol. 8, pp. 1-10, Jul. 2013.

[9] M. A. Clarke, J. L. Moore, L. M. Steege, R. J. Koopman, J. L. Belden, S. M. Canfield, S. E. Meadows, S. G. Elliott and M. S. Kim, "Health information needs, sources, and barriers of primary care patients to achieve patient-centered care: A literature review," Health Informatics Journal, pp. 1-25, Sep. 2015.

[10] WHO Expert Consultation, "Appropriate body-mass index for Asian populations and its implications for policy and intervention strategies," The Lancet, vol. 363, pp. 157-163, Jan. 2004.

[11] World Health Organization, The Asia-Pacific Perspective: Redefining Obesity and Its Treatment, Sydney, Australia: World Health Organization, 2000.

[12] S. Soraya, "Pengambilan lemak dan suplemen antioksidan di kalangan pesakit hiperlipidemia yang telah menerima rawatan diet di Klinik Diet, HUKM,” B. Sc. thesis, Universiti Kebangsaan Malaysia, Selangor, Malaysia, Jul. 2004. 
[13] Y. Kim, I. Park and M. Kang, "Convergent validity of the international physical activity questionnaire (IPAQ): Meta-analysis," Public Health Nutrition, vol. 16, pp. 440-452, Mar. 2013.

[14] M. Koikkalainen, R. Lappalainen and H. Mykkänen, "Why cardiac patients do not follow the nutritionist's advice: Barriers in nutritional advice perceived in rehabilitation," Disability and Rehabilitation, vol. 18, pp. 619-623, Dec. 1996.

[15] J. Hsia, R. Rodabough, M. C. Rosal, B. Cochrane, B. V. Howard, L. Snetselaar, W. H. Frishman and M. L. Stefanick, "Compliance with national cholesterol education program dietary and lifestyle guidelines among older women with self-reported hypercholesterolemia: The women's health initiative," The American Journal of Medicine, vol. 113, pp. 384-392, Oct. 2002.

[16] P. Wiegand, J. S. McCombs and J. J. Wang, "Factors of hyperlipidemia medication adherence in a nationwide health plan," The American Journal of Managed Care, vol. 18, pp. 193-199, Apr. 2012.

[17] G. Xie, M. J. S. Zaman, P. K. Myint, L. Liang, L. Zhao and Y. Wu, "Factors associated with compliance to lipid-lowering treatment in China," European Journal of Preventive Cardiology, vol. 20, pp. 229237, Apr. 2013.

[18] D. J. Jenkins, P. J. Jones, B. Lamarche, C. W. Kendall, D. Faulkner, L. Cermakova, I. Gigleux, V. Ramprasath, R. de Souza, C. Ireland and D. Patel, "Effect of a dietary portfolio of cholesterol-lowering foods given at 2 levels of intensity of dietary advice on serum lipids in hyperlipidemia: a randomized controlled trial," Journal of the American Medical Association, vol. 306, pp. 831-839, Aug. 2011.

[19] S. Kelly, S. Martin, I. Kuhn, A. Cowan, C. Brayne and L. Lafortune, "Barriers and facilitators to the uptake and maintenance of healthy behaviours by people at mid-life: A rapid systematic review," PLoS One, vol. 11, pp. 1-26, Jan. 2016.

[20] T. K. Ng, "Towards improved fat intake and nutrition for Malaysians," Malaysian Journal of Nutrition, vol. 1, pp. 21-30, Mar. 1995

[21] World Health Organization, Diet, Nutrition and the Prevention of Chronic Diseases, New Delhi, India: Diamond Pocket Books (P) Ltd, 2003.

[22] G. Vannice and H. Rasmussen, "Position of the academy of nutrition and dietetics: Dietary fatty acids for healthy adults," Journal of the Academy of Nutrition and Dietetics, vol. 114, pp. 136-153, Jan. 2014.

[23] M. P. St-Onge, I. Aban, A. Bosarge, B. Gower, K. D. Hecker and D. B. Allison, "Snack chips fried in corn oil alleviate cardiovascular disease risk factors when substituted for low-fat or high-fat snacks,"
The American Journal of Clinical Nutrition, vol. 85, pp. 1503-1510, Jun. 2007.

[24] M. Kruse, C. von Loeffelholz, D. Hoffmann, A. Pohlmann, A. C Seltmann, M. Osterhoff, S. Hornemann, O. Pivovarova, S. Rohn, G. Jahreis and A. F. Pfeiffer, "Dietary rapeseed/canola-oil supplementation reduces serum lipids and liver enzymes and alters postprandial inflammatory responses in adipose tissue compared to olive-oil supplementation in obese men," Molecular Nutrition and Food Research, vol. 59, pp. 507-519, Mar. 2015.

[25] Y. Li, A. Hruby, A. M. Bernstein, S. H. Ley, D. D. Wang, S. E. Chiuve, L. Sampson, K. M. Rexrode, E. B. Rimm, W. C. Willett and F. B. Hu, "Saturated fats compared with unsaturated fats and sources of carbohydrates in relation to risk of coronary heart disease: A prospective cohort study," Journal of the American College of Cardiology, vol. 66, pp. 1538-1548, Oct. 2015.

[26] R. J. Widmer, A. J. Flammer, L. O. Lerman and A. Lerman, "The Mediterranean diet, its components, and cardiovascular disease," The American Journal of Medicine, vol. 128, pp. 229-238, Mar. 2015.

[27] J. A. Marlett, Dietary Fiber and Cardiovascular Disease, ser Handbook of Dietary Fiber, S. S. Cho and M. L. Dreher, Eds. New York, USA: Marcel Dekker Inc, 2001.

[28] L. Brown, B. Rosner, W. W. Willett and F. M. Sacks, "Cholesterollowering effects of dietary fiber: A meta-analysis," The American Journal of Clinical Nutrition, vol. 69, pp. 30-42, Jan. 1999.

[29] A. E. Bauman, R. S. Reis, J. F. Sallis, J. C. Wells, R. J. Loos, B. W. Martin and Lancet Physical Activity Series Working Group, "Correlates of physical activity: Why are some people physically active and others not?" The Lancet, vol. 380, pp. 258-271, Jul. 2012.

[30] S. A. Sliwa, A. Must, F. Peréa and C. D. Economos, "Maternal employment, acculturation, and time spent in food-related behaviors among Hispanic mothers in the United States: Evidence from the American time use survey," Appetite, vol. 87, pp. 10-19, Apr. 2015.

[31] M. Carrigan, I. Szmigin and S. Leek, "Managing routine food choices in UK families: The role of convenience consumption," Appetite, vol. 47, pp. 372-383, Nov. 2006

[32] H. Luomala, M. Jokitalo, H. Karhu, H. L. Hietaranta-Luoma, A Hopia and S. Hietamäki, "Perceived health and taste ambivalence in food consumption," Journal of Consumer Marketing, vol. 32, pp. 290-301, Jul. 2015.

[33] N. Darmon and A. Drewnowski, "Contribution of food price and diet cost to socioeconomic disparities in diet quality and health: A systematic review and analysis," Nutrition Review, vol. 73, pp. 643 660 , Oct. 2015. 